\title{
Prestress Losses in Concrete Rafters with Openings
}

\author{
Falah Jarass Aied Alkhafaji \\ Department of Civil Engineering \\ College of Engineering \\ University of Baghdad, Iraq \\ falahgaras@gmail.com
}

\author{
Amer Farouk Izzet \\ Department of Civil Engineering \\ College of Engineering \\ University of Baghdad, Iraq \\ amer.f@coeng.uobaghdad.edu.iq
}

\begin{abstract}
In this paper, experimental work was conducted to evaluate the losses in prestressing force of 13 (12 perforated and 1 solid) simply supported prestressed concrete rafters. All beams had the same dimensions and reinforcements. The tested beams were divided into four main groups and three additional subgroups were driven. These groups were classified according to size, number, and configuration of the openings, and the orientation of the posts (vertical or inclined). Regarding the prestress losses that have been affected by the cross-section properties, the provision of the codes is applicable only to prismatic solid beams, so non-prismatic or moreover perforated beams also need to be studied. This paper aims to propose a method based on the same code provisions but taking into consideration the cross-section variation along the beam length. The proposed method divides the overall length of the rafter into a number of assumed prismatic segments with heights measured at centers. Then, the overall prestress loss is found as the sum of these segments weighed by the ratios of the length of each beam segment to the overall length. The experimental results of the proposed method ranged from $84.749 \%$ to $95.607 \%$ denoting its validity.
\end{abstract}

\section{Keywords-prestress losses; rafter beams; openings}

\section{INTRODUCTION}

The stresses in the tendons of prestressed concrete members are decreasing with time, but at a decreasing rate, and asymptotically level off after a long time. The total stress reduction during the lifespan of the member is called total prestress loss [1-3]. The reduction in the prestressing force can be grouped into two categories:

- Immediate elastic loss during the fabrication or construction process, including elastic shortening of the concrete, anchorage losses, and frictional losses.

- Time-dependent losses such as creep, shrinkage, and those due to temperature effects and steel relaxation, all of which are determinable at the service-load limit state of stress in the prestressed concrete element.

An exact determination of the magnitude of these losses, particularly the time-dependent ones, is not feasible, since they depend on many interrelated factors. Empirical methods of estimating losses differ with the different codes of practice or recommendations. The degree of rigor of these methods depends on the approach chosen and the accepted practice of record [4-5].
The presence of openings in gable reinforced concrete beams has many advantages such as flexibility, easier handling, and, most importantly, reduced overall weight. Furthermore, concrete has very low to no maintenance cost and high fire resistance, therefore reinforced concrete gable beams can be used as a good alternative option to design roofs for warehouses, industrial buildings, and airplane hangars instead of steel sections [6-10]. The link structural elements (posts) between the upper and the lower chords of the rafter beam have many advantages such as avoiding Vierendeel truss to prevent shear failure and allowing a beam to enhance its bending capacity and ductility [11]. The fact that concrete is not efficient in resisting tensile stress makes very difficult reaching a long span beam in design, so the addition of prestressing reinforcements has become necessary to reach span lengths which cannot be reached by using ordinary reinforcements [1213]. To estimate losses such as elastic shortening, creep, shrinkage, and relaxation in beams, the empirical methods recommended by the codes are only applicable to prismatic beams. No special recommendations have been included regarding rafter beams with or without openings. This study has proposed a method to estimate prestress losses in rafter beams, which are divided into a number of segments that are assumed to be prismatic along their lengths with heights measured at centers.

\section{EXPERIMENTAL INVESTIGATION}

The experimental program consisted of casting and testing of 13 rafter beams, including 12 beams with openings (perforated) and one reference solid beam without openings. All the tested beams had the same rafter geometry, i.e. a rectangular cross-section of $100 \mathrm{~mm}$ width and height of $400 \mathrm{~mm}$ at center tapered to $250 \mathrm{~mm}$ at the two ends, while the overall length was $3000 \mathrm{~mm}$ with a clear span of $2800 \mathrm{~mm}$. Figure 1 shows the geometrical details of the tested beams. Figures 2 and 3 exhibit the details of the solid prestressed rafter concrete beam and the beams with openings respectively. Mild steel reinforcement of 4,6 , and $12 \mathrm{~mm}$ bar diameters were used while seven-wire low-relaxation strands, Grade 270 with $\varnothing 12.7 \mathrm{~mm}$ diameter were used as prestressing steel. The tested beams were divided into four main groups (A, B, C, and D). These groups were classified according to the studied variables which are: size, openings number, posts inclination, and configuration of the openings. Table I exhibits the grouping according to these variables as follows: 


\section{- Main groups}

To study the effect of openings' width versus the number of openings along the beam length, it is worth to highlight that Group A and B had vertical posts whereas Group C had inclined posts. Group A and C had the same upper and lower chords depth of $100 \mathrm{~mm}$ whereas it was $75 \mathrm{~mm}$ for Group B. Group D has been prepared in order to study the effect of the increasing of the opening area in the case of using the same number of circular openings.

\section{- Subgroups}

Group $\mathrm{E}$ has been driven to investigate the effect of increasing opening height or in other words decreasing depth of the upper and lower chords of the beam (beams have been taken from Groups A and B). Group F was driven to find the effect of post configurations linked between the upper and lower beam chords, i.e. the geometric shape of the quadratic openings (beams have been adopted from Groups A and C). Group $\mathrm{G}$ consists of beams with the same number of openings but with different openings configurations in order to compare circular and quadratic openings (beams have been chosen from Groups A, B, C and D).

\section{A. Measurements of Prestress Losses}

Prestress losses were determined at different stages (at transfer of prestressing force and just before loading test). A special high accuracy electrical resistance measuring device was used for this purpose. Electrical resistance strain gauges (FLA-6-11, length $=6 \mathrm{~mm}$ ) with gauge factor of $2.09 \pm 1 \%$, and resistance of $120.4 \Omega$ were fixed on the strand and bridged to the data logger. An initial reading was recorded on applying the prestressing force, and another reading was conducted before the load test. The electrical resistance is converted to strain through the following equation:

$$
\varepsilon=\frac{R_{0}-R_{i}}{k R_{0}}
$$

where $R o=$ initial electrical resistance at the moment of prestress transfer, $R i=$ electrical resistance immediately before testing, and $K=$ strain gauge factor (for this type of strain gauge, $K=2.09$ ). Through (1) the electrical resistance is converted to strain. This strain is compared with the strain calculated from the elongation which was measured immediately after applying the prestressing [14].

\section{B. Prestressing Process}

For post-tensioning concrete gable beams, after attaining the age of 57 days for concrete, the prestressing process has been done according to the following sequence:

- After fixing the strain gauges on the strand (7-wire strand, $12.7 \mathrm{~mm}$ diameter), it was inserted through the PVC duct which has been embedded in the mold before concrete casting.

- Bridging the strain gauges wires to strain indicator (data logger)

- Attaching the predesigned end bearing steel plates with adequate grips at the beam ends.

- Applying the prestressing force $(110 \mathrm{kN})$ from one end according to the ACI-318M-14 [15] limitations.

- Finally, releasing the jack and measuring the strand elongation and the strain which has been occurred in the strand. The corresponding strain was monitored and compared with the reading of the pressure gauge of the hydraulic jack.

TABLE I. DETAILS OF TESTED BEAMS

\begin{tabular}{|c|c|c|c|c|c|c|c|}
\hline Group & $\begin{array}{l}\text { Beam } \\
\text { mark }\end{array}$ & Shape of openings & $\begin{array}{c}\text { Number of } \\
\text { openings }\end{array}$ & $\begin{array}{c}\text { Total area of } \\
\text { openings }\left(\mathrm{mm}^{2}\right)\end{array}$ & $\begin{array}{c}\text { Width of } \\
\text { openings }(\mathrm{mm})\end{array}$ & $\begin{array}{c}\text { Height of upper } \\
\text { chord (mm) }\end{array}$ & $\begin{array}{c}\text { Height of lower } \\
\text { chord (mm) }\end{array}$ \\
\hline \multirow{4}{*}{ A } & PGB & ------ & ----- & 0 & ----- & ----- & ----- \\
\hline & PGT6 & Trapezoidal & 6 & 180000 & 200 & 100 & 100 \\
\hline & PGT8 & Trapezoidal & 8 & 174000 & 150 & 100 & 100 \\
\hline & PGT10 & Trapezoidal & 10 & 144000 & 100 & 100 & 100 \\
\hline \multirow{4}{*}{ B } & PGB & ----- & ----- & 0 & ----- & ----- & ----- \\
\hline & PGTH6 & Trapezoidal & 6 & 240000 & 200 & 75 & 75 \\
\hline & PGTH8 & Trapezoidal & 8 & 234000 & 150 & 75 & 75 \\
\hline & PGTH10 & Trapezoidal & 10 & 195000 & 100 & 75 & 75 \\
\hline \multirow{4}{*}{$\mathrm{C}$} & PGB & ------ & ------ & 0 & ------ & ------ & ------ \\
\hline & PGP6 & $\begin{array}{l}\text { Trapezoidal with } \\
\text { inclined posts }\end{array}$ & 6 & 154000 & 200 & 100 & 100 \\
\hline & PGP8 & $\begin{array}{l}\text { Trapezoidal with } \\
\text { inclined posts }\end{array}$ & 8 & 151000 & 150 & 100 & 100 \\
\hline & PGP10 & $\begin{array}{l}\text { Trapezoidal with } \\
\text { inclined posts }\end{array}$ & 10 & 138000 & 100 & 100 & 100 \\
\hline \multirow{4}{*}{$\mathrm{D}$} & PGB & ------ & ------ & 0 & ------ & ------ & ------ \\
\hline & PGC1 & Circular & 8 & 184200 & $\mathrm{D}$ & 75 & 75 \\
\hline & PGC2 & Circular & 8 & 128000 & $0.83 \mathrm{D}$ & 100 & 100 \\
\hline & PGC3 & Circular & 8 & 82000 & $0.67 \mathrm{D}$ & 120 & 120 \\
\hline
\end{tabular}



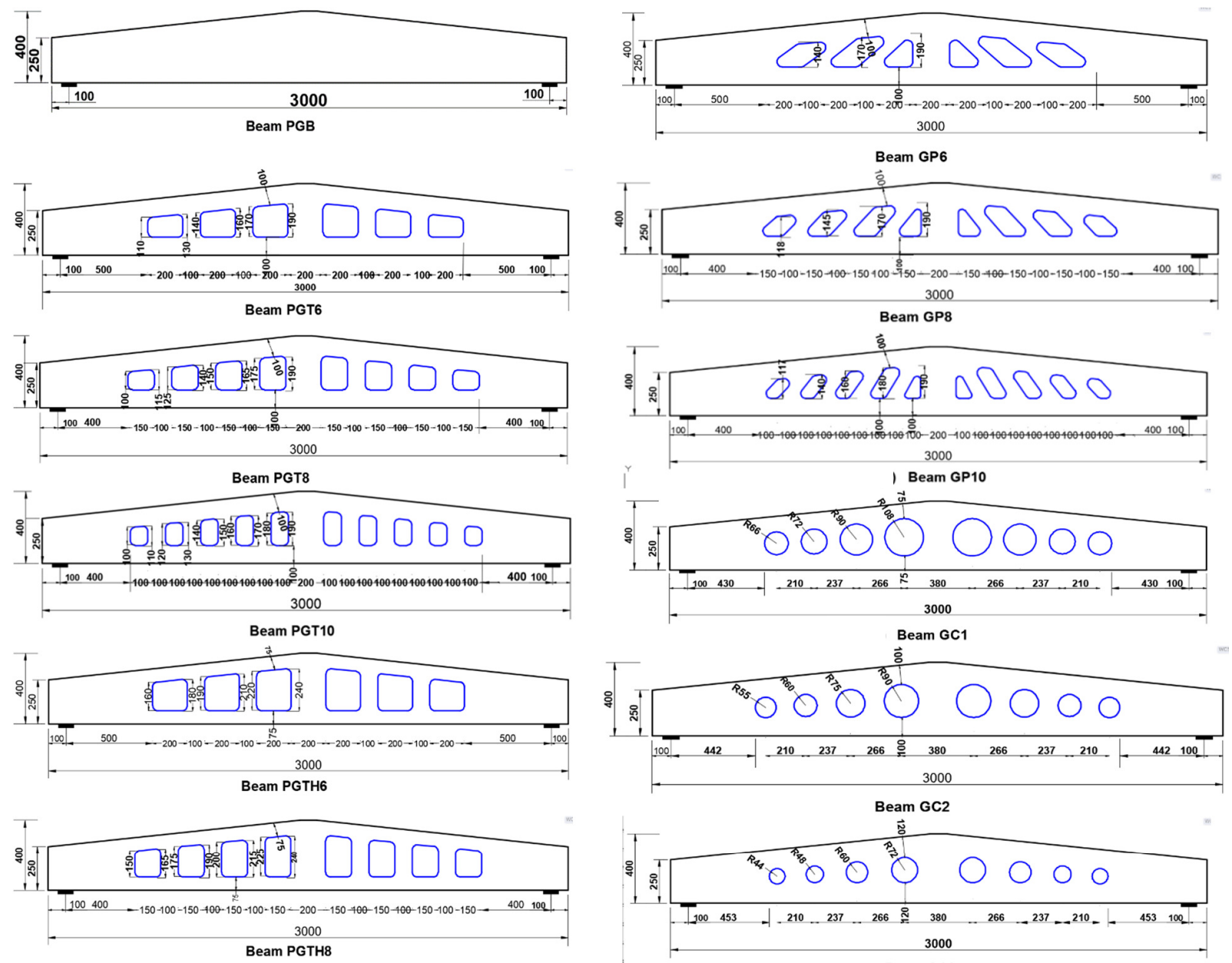

Beam GC3

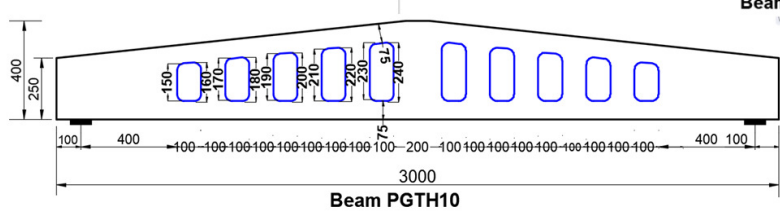

Fig. 1. Geometrical details of the tested beams

\section{EXPERIMENTAL RESULTS AND DISCUSSION}

The prestressing losses were monitored. These losses result from end anchorage slip, strand friction with the duct, strand relaxation and shrinkage, and creep of concrete. Table II shows the prestress losses and the residual prestress (effective prestress). It was observed that the losses ranged from $17.465 \%$ to $20.309 \%$ of the initial prestress depending on size, number of openings, posts inclination, and openings configuration.

The effect of the considered parameters on the prestress losses are: For Group $\mathrm{A}, \mathrm{B}$, and $\mathrm{C}$, when the number of openings increases, the prestress losses decrease. This might be due to the minimization of total area of openings and increasing number of posts which have a positive effect on prestress losses and the behavior of the beam in general. The following comparison demonstrates the decreasing ratio in prestress losses with increasing number of openings:
- Group A: 2.558 and 4.33\% for PGT8 and PGT10 beams respectively in relation to beam PGT6.

- Group B: 2.175 and 3.403\% for PGTH8 and PGTH10 beams respectively in relation to beam PGTH6.

- Group C: 2.888 and 4.764\% for PGP8 and PGP10 beams respectively in relation to beam PGP6.

- Group D (circular openings) it can be noticed that, the prestress losses decrease with reducing size of circular openings. The decreasing ratio was $4.25 \%$ and $6.441 \%$ for $\mathrm{GC} 2$ and $\mathrm{GC} 3$ beams respectively in relation to $\mathrm{GC} 1$.

- Group E compares the beams of Groups A and B. The decreasing depth of both upper and lower chords (Group B) by $25 \%$ (elative to that of Group A) led to reduced prestress losses by $3.824 \%$ for beam PGT6 related to beam PGTH6 (Group EI), $4.201 \%$ for beam PGT8 related to beam 
PGTH8 (Group EII), and 4.749\% for beam PGT10 related to beam PGTH10 (Group EIII) respectively.

- Group F consists of a comparison between the beams of Groups $\mathrm{A}$ and $\mathrm{C}$. The beams of the two groups have the same number of openings and post dimensions but they differ in their inclinations. The prestress losses were $0.438 \%$ for beam PGP6 related to beam PGT6 (Group FI), $0.775 \%$ for beam PGP8 related to beam PGT8 (Group FII), and $6.567 \%$ for beam PGP10 related to beam PGT10 (Group FIII).

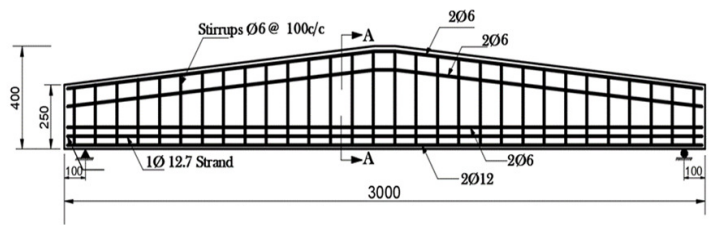

(a)

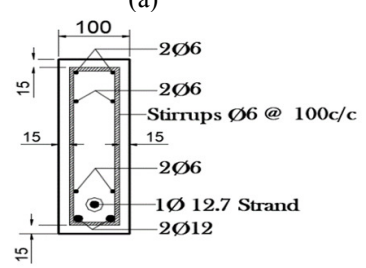

(b)

Fig. 2. (a) Reinforcement details for solid rafter PGB, (b) section A-A (all dimensions are in $\mathrm{mm}$ )

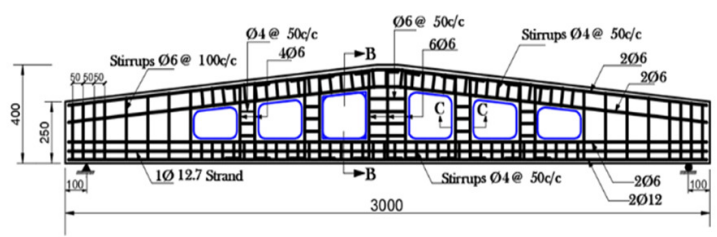

(a)

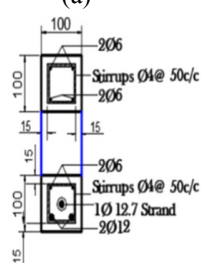

(b)

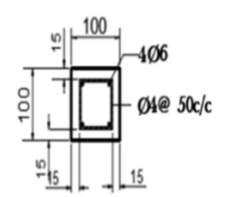

(c)

Fig. 3. (a) Details of reinforcement for rafter with openings PGT6, (b) section B-B, (c) section C-C

- Group $\mathrm{G}$ consists of beams having eight openings but different configurations (circular and quadratic openings), with both opening shapes are restricted by the same chord depth. The results indicate a decrease in the prestress losses on the beams with circular openings in comparison with the beams with quadratic openings. The decrease ratios are: $2.488 \%$ for beam PGC2 related to beam PGT8 (Group GI), $2.437 \%$ for beam PGC1 related to beam PGTH8 (Group GII), and $1.726 \%$ for beam PGC2 related to beam PGP8 (Group GIII).

\section{PRESTRESS LOSSES WITH THE PROPOSED METHOD}

The variation in cross-section properties should be considered in order to calculate the prestress losses in solid or perforated rafter beams. The method suggests dividing a rafter beam into a set of segments that are considered as prismatic parts with heights measured at centers (Figure 4). For the perforated beams, the number of segments should be chosen in a manner such that the segment is either solid or with openings. The overall prestress loss is found as the summation of the contributions of the beam subdivisions weighed by the ratio of the length of the beam segment to the overall length. The PGT6 beam has been taken as an example to show the steps of the estimation process in details. The same procedure was used for the other tested beams.

\section{1) Instantaneous Losses}

a) Anchorage Seating Loss

Usually long tendons will be less affected by seating loss. For short tendons, the seating loss should be detected and subtracted from the applied prestressing force [16]. Assuming $\Delta A=1.5 \mathrm{~mm}$ and $L=3000 \mathrm{~mm}$ and by (2):

$$
\Delta f_{P A}=\frac{\Delta_{A}}{L} E_{P}
$$

substituting we get $\Delta f_{P A}=98.75 \mathrm{MPa}$.

\section{b) Elastic Shortening}

No elastic shortening occurred because only one strand was used in each beam: $\Delta f_{E S}=0$

\section{c) Friction Losses}

The strand is straight therefore there is no curvature, $\alpha=0$. Assuming that wobble coefficient $k=0.002$, by (3) we get:

$$
\Delta f_{P F}=f_{p i}(\mu \alpha+k L)
$$

substituting we get: $\Delta f_{P F}=6.25 \mathrm{MPa}$. The stress remaining in the restressing strand after all instantaneous stresses is:

$$
f_{p i}=f_{p j}-\left(\Delta f_{P A}+\Delta f_{E S}+\Delta f_{P F}\right)
$$

substituting we get: $f_{p i}=116-(105.8+6.25)=1003.95 \mathrm{Mpa}$. The net prestressing force is calculated by:

$$
P_{i}=f_{p i} A_{p s}
$$

substituting we get: $P_{i}=f_{p i} A_{p s}=99391 \mathrm{~N}$.

2) Time Dependent Losses

a) Stage (I): Losses After $24 \mathrm{hr}$ of the Force Transfer

- Relaxation loss:

For $t_{1}=1 \mathrm{hr}, t_{2}=24 \mathrm{hr}$ :

$$
\Delta f_{P R}=f_{p i}\left(\frac{\log t_{2}-\log t_{1}}{10}\right)\left(\frac{f_{p i}}{f_{p y}}-0.55\right)
$$

substituting we get: $\Delta f_{P R}=6.89 \mathrm{MPa}$. 
TABLE II. PRESTRESS LOSSES AND STRESSES IN PRESTRESSED CONCRETE BEAMS UP TO THE MOMENT OF TESTING

\begin{tabular}{|c|c|c|c|c|c|c|c|c|c|c|}
\hline Group & $\begin{array}{l}\text { Beam's } \\
\text { labeling }\end{array}$ & $\begin{array}{c}\text { Prestress } \\
\text { stress } \\
\text { (MPa) }\end{array}$ & $\begin{array}{c}\text { Age of } \\
\text { beam at } \\
\text { testing } \\
\text { (days) } \\
\end{array}$ & $\begin{array}{c}\text { Age of beam } \\
\text { transferred to } \\
\text { testing (days) }\end{array}$ & $\begin{array}{c}\text { Instantaneous } \\
\text { losses after } \\
\text { transfer (MPa) }\end{array}$ & $\begin{array}{l}\text { Time dependent } \\
\text { losses at testing } \\
\text { (MPa) }\end{array}$ & \begin{tabular}{|c|} 
Total \\
prestress \\
losses, \\
$(\mathrm{MPa}) \Delta P F T$ \\
\end{tabular} & \begin{tabular}{|c|} 
Residual \\
prestress in \\
strands, (effective \\
prestress) (MPa) \\
\end{tabular} & \begin{tabular}{|c|} 
Presstress \\
loss/initial \\
prestress (\%)
\end{tabular} & $\begin{array}{l}\text { Increasing } \\
\text { ratio of } \\
\text { losses\% (1) }\end{array}$ \\
\hline \multicolumn{11}{|c|}{ Main groups } \\
\hline \multirow{4}{*}{ A } & PGB & 1116 & 105 & 48 & 100.313 & 94.596 & 194.909 & 921.090 & 17.465 & 0 \\
\hline & PGT6 & 1116 & 115 & 58 & 107.088 & 110.894 & 217.982 & 898.0176 & 19.533 & 11.837 \\
\hline & PGT8 & 1116 & 120 & 63 & 105.494 & 106.912 & 212.406 & 903.594 & 19.033 & 8.9766 \\
\hline & PGT10 & 1116 & 122 & 65 & 104.751 & 103.787 & 208.538 & 907.462 & 18.686 & 6.9922 \\
\hline \multirow{4}{*}{ B } & PGB & 1116 & 105 & 48 & 100.313 & 94.596 & 194.909 & 921.091 & 17.465 & 0 \\
\hline & PGTH6 & 1116 & 123 & 66 & 105.122 & 121.528 & 226.650 & 889.350 & 20.309 & 16.284 \\
\hline & PGTH8 & 1116 & 125 & 68 & 104.244 & 117.476 & 221.720 & 894.280 & 19.867 & 13.755 \\
\hline & PGTH10 & 1116 & 127 & 70 & 105.208 & 113.729 & 218.936 & 897.063 & 19.618 & 12.327 \\
\hline \multirow{4}{*}{$\mathrm{C}$} & PGB & 1116 & 105 & 48 & 100.313 & 94.596 & 194.909 & 921.090 & 17.465 & 0 \\
\hline & PGP6 & 1116 & 128 & 71 & 101.489 & 115.539 & 217.028 & 898.972 & 19.447 & 11.348 \\
\hline & PGP8 & 1116 & 129 & 72 & 97.996 & 112.764 & 210.760 & 905.240 & 18.885 & 8.1322 \\
\hline & PGP10 & 1116 & 130 & 73 & 105.789 & 100.899 & 206.688 & 909.312 & 18.520 & 6.0427 \\
\hline \multirow{3}{*}{$\mathrm{D}$} & PGB & 1116 & 105 & 48 & 100.313 & 94.596 & 194.909 & 921.091 & 17.465 & 0 \\
\hline & PGC2 & 1116 & 132 & 75 & 97.727 & 109.396 & 207.123 & 908.878 & 18.559 & 6.2657 \\
\hline & PGC3 & 1116 & 133 & 76 & 103.649 & 98.733 & 202.382 & 913.618 & 18.135 & 3.8338 \\
\hline \multicolumn{11}{|c|}{ Secondary groups } \\
\hline \multirow{3}{*}{ EI } & PGB & 1116 & 105 & 48 & 100.313 & 94.596 & 194.909 & 921.091 & 17.465 & 0 \\
\hline & PGT6 & 1116 & 115 & 58 & 107.088 & 110.894 & 217.982 & 898.018 & 19.533 & 11.837 \\
\hline & PGTH6 & 1116 & 123 & 66 & 105.122 & 121.528 & 226.650 & 889.350 & 20.309 & 16.284 \\
\hline \multirow{3}{*}{ EII } & PGB & 1116 & 105 & 48 & 100.313 & 94.596 & 194.909 & 921.091 & 17.465 & 0 \\
\hline & PGT8 & 1116 & 120 & 63 & 105.494 & 106.912 & 212.406 & 903.593 & 19.033 & 8.9766 \\
\hline & PGTH8 & 1116 & 125 & 68 & 104.244 & 117.476 & 221.720 & 894.240 & 19.867 & 13.755 \\
\hline \multirow{3}{*}{ EIII } & PGB & 1116 & 105 & 48 & 100.313 & 94.596 & 194.909 & 921.091 & 17.465 & 0 \\
\hline & PGT10 & 1116 & 122 & 65 & 104.751 & 103.787 & 208.538 & 907.462 & 18.686 & 6.992 \\
\hline & PGTH10 & 1116 & 127 & 70 & 105.207 & 113.729 & 218.937 & 897.063 & 19.618 & 12.327 \\
\hline \multirow{3}{*}{ FI } & PGB & 1116 & 105 & 48 & 100.313 & 94.596 & 194.909 & 921.091 & 17.465 & 0 \\
\hline & PGT6 & 1116 & 115 & 58 & 107.088 & 110.894 & 217.982 & 898.018 & 19.533 & 11.837 \\
\hline & PGP6 & 1116 & 128 & 71 & 101.489 & 115.539 & 217.027 & 898.973 & 19.447 & 11.348 \\
\hline FII & PGB & 1116 & 105 & 48 & 100.313 & 94.596 & 194.909 & 921.091 & 17.465 & 0 \\
\hline \multirow{3}{*}{ FIII } & PGB & 1116 & 105 & 48 & 100.313 & 94.596 & 194.909 & 921.091 & 17.465 & 0 \\
\hline & PGT10 & 1116 & 122 & 65 & 104.751 & 116.464 & 221.215 & 894.785 & 19.822 & 6.640 \\
\hline & PGP10 & 1116 & 130 & 73 & 105.789 & 100.899 & 206.688 & 909.312 & 18.520 & 6.043 \\
\hline \multirow{3}{*}{ GI } & PGB & 1116 & 105 & 48 & 100.3134 & 94.596 & 194.9094 & 921.0906 & 17.465 & 0 \\
\hline & PGT8 & 1116 & 120 & 63 & 105.4942 & 106.912 & 212.4062 & 903.5938 & 19.0328 & 8.9766 \\
\hline & PGC2 & 1116 & 132 & 75 & 97.72652 & 109.396 & 207.1225 & 908.8775 & 18.5594 & 6.2657 \\
\hline \multirow{3}{*}{ GII } & PGB & 1116 & 105 & 48 & 100.3134 & 94.596 & 194.9094 & 921.0906 & 17.465 & 0 \\
\hline & PGTH8 & 1116 & 125 & 68 & 104.244 & 117.476 & 221.72 & 894.28 & 19.8674 & 13.755 \\
\hline & PGC1 & 1116 & 131 & 74 & 98.01274 & 118.303 & 216.3157 & 899.6843 & 19.3831 & 10.982 \\
\hline \multirow{3}{*}{ GIII } & PGB & 1116 & 105 & 48 & 100.3134 & 94.596 & 194.9094 & 921.0906 & 17.465 & 0 \\
\hline & PGP8 & 1116 & 129 & 72 & 97.99647 & 112.764 & 210.7605 & 905.2395 & 18.8853 & 8.1322 \\
\hline & PGC2 & 1116 & 132 & 75 & 97.72652 & 109.396 & 207.1225 & 908.8775 & 18.5594 & 6.2657 \\
\hline
\end{tabular}

- Creep loss: $\Delta f_{C R}=0$

- Shrinkage loss: $\Delta f_{S H}=0$

- Tendon stress at the end of Stage I:

$$
f_{p s}=f_{p i}-\Delta f_{P R}
$$

substituting we get: $f_{p s}=997.06 \mathrm{MPa}$.

b) Stage (II): Losses after 58 Days:

- Creep loss: $P_{i}=f_{p i} A_{p s}=98.709 \mathrm{kN}$

$$
\mathrm{r}^{2}=\frac{I_{C}}{A_{C}}
$$

$$
\dot{\mathrm{f}}_{c s i}=-\frac{P_{i}}{A_{C}} \times\left(1+\frac{e_{i}^{2}}{r_{i}^{2}}\right)+\frac{M D_{i} e_{i}}{I_{C}}
$$

For part No.1: $i=1, l_{l}=0.6 \mathrm{~m}$ (length of segment), $X_{I}=0.3 \mathrm{~m}$, $Y_{l}=\frac{0.15}{1.45} \times 0.3=0.031 \mathrm{~m}, H_{l}=0.25+Y_{l}=0.281 \mathrm{~m} \quad$ (height of sectional center of segment), $B_{l}=0.1 \mathrm{~m}$ (beam width), $A_{I}=B_{1} \times H_{1}=0.0281 \mathrm{~m}^{2}$ (cross section area of segment), so:

$I_{l}=\frac{B_{1} \times H_{1}}{12}=0.00018497 \mathrm{~m}^{2}, \quad r_{i}^{2}=\frac{I_{C 1}}{A_{C 1}}=0.00658 \mathrm{~m}^{2} \quad$ and $e_{1}=\left(\frac{H_{1}}{2}-C s g\right)=0.0905 \mathrm{~m}$. Taking as $h=0.25 \mathrm{~m}$ we have: 
$w_{1}=B_{1} \times h \times \chi_{c}=0.6 \mathrm{kN} / \mathrm{m}$ and $w_{2}=0.0155 \mathrm{kN} / \mathrm{m} . \quad R$ is: $R=\frac{\left(V_{T}-V_{\text {opening }}\right) \times x_{C}}{2}=0.963 \mathrm{kN}$, and:

$$
\begin{gathered}
M D_{I}=R \times l_{1}-\left(w_{1} \times l_{1} \times x_{1}+w_{2} \times \frac{l_{2}}{2} \times x_{2}\right)=0.2617 \\
\dot{\mathrm{f}}_{c s i}=-\frac{P_{1}}{A_{c 1}} \times\left(1+\frac{e_{1}^{2}}{r_{1}^{2}}\right)+\frac{M D_{1} e_{1}}{I c i}=7.75769 \mathrm{MPa} .
\end{gathered}
$$

With $\dot{\mathrm{f}}_{c s i} \times \frac{l_{i}}{L}=3.103 \mathrm{MPa}$ we have:

$$
\begin{array}{r}
\dot{\mathrm{f}}_{c s}=\sum_{i=1}^{n} \dot{\mathrm{f}}_{c s i} \times \frac{l_{i}}{L} \\
E_{c}=4700 \times \sqrt{f^{\prime} c} \\
n=\frac{E_{p s}}{E_{c}} \quad(12)
\end{array}
$$

substituting in (10)-(12) we get: $\dot{\hat{f}}_{C S}=7.718 \mathrm{MPa}, E_{C}=29725$, and $n=6.65$. For a posttensioned beam: $K_{C R}=1.6$, so:

$$
\Delta f_{P C R}=n K_{C R} \dot{\mathrm{f}}_{C S}
$$

substituting we have $\Delta f_{P C R}=82.12 \mathrm{MPa}$. The same steps are repeated for the other segments (portions) of the beam, and then the total prestress loss due to the creep is found after multiplying $f_{c s i}$ by $L_{i} / L$ for all segments as in (10). The calculations are shown in Table III.

- Shrinkage loss:

$$
\begin{gathered}
\Delta f_{S H i}=2.8 \times 10^{-6} K S H_{i} \mathrm{E}_{\mathrm{ps} i}\left(1-0.06 \frac{V_{i}}{S_{i}}\right)\left(100-R H_{i}\right) \\
\Delta f_{S H}=\sum_{i=1}^{n} \Delta f S H_{i} \times \frac{l i}{L}
\end{gathered}
$$

For $i=1, \quad l_{l}=0.6 \mathrm{~m}, X_{l}=0.3 m, \quad Y_{l}=31.034 \mathrm{~mm}$ we get: $H_{1}=281.03 \mathrm{~mm}, \quad B_{l}=100 \mathrm{~mm}, \mathrm{~V}_{\mathrm{i}}=28103 \mathrm{~mm}^{2}, \quad S_{l}=\left(B_{I}+H_{1}\right) \times 2$ $=762.069 \mathrm{~mm}^{2}$ (surface area of segment), $K_{S H}=0.77, R H=70 \%$, $E_{p s i}=197500$,and:

$$
\begin{aligned}
& \Delta f S H_{1}=2.8 \times 10-6 K S H_{i} \mathrm{E}_{\mathrm{psi}}\left(1-0.06 \frac{V_{i}}{S_{i}}\right)\left(100-R H_{i}\right)=> \\
& \Delta f S H i=34.0994, \text { while } \Delta f S H_{1} \times \frac{l 1}{L}=13.6397845 \mathrm{MPa} \text { and } \\
& \Delta f S H=\sum_{i=1}^{n} \Delta f S H_{i} \times \frac{l i}{L}=34.48 \mathrm{MPa} .
\end{aligned}
$$

The same steps are repeated for the other segments of the beam, and then the total prestress loss due to shrinkage is the cumulative summarization of the $\Delta f S H_{i}$ multiplied by $L_{i} / L$ for all parts as in (15). The calculations are shown in Table IV.

c) Relaxation Loss after 43 Days

$f_{p s}=997.06 \mathrm{Mpa}, t_{1}=24 \mathrm{hr}, t_{2}=1032 \mathrm{hr}$, and

$$
\Delta \mathrm{f}_{\mathrm{PR}}=f_{p i}\left(\frac{\log _{\mathrm{t} 2}-\log _{\mathrm{t} 1}}{10}\right)\left(\frac{f_{p i}}{f_{p y}}-0.55\right)=8.02 \mathrm{MPa} \text {. The total }
$$

\begin{tabular}{|c|c|c|c|c|c|c|c|c|c|c|c|c|c|c|}
\hline Part No. & $i$ & $l_{i}$ & $X_{i}$ & $Y_{i}$ & $\boldsymbol{H}_{i}$ & $B_{i}$ & $A_{c i}$ & $I_{c i}$ & $r_{i}{ }_{i}$ & $e_{i}$ & $p_{i}$ & $M D_{i}$ & $\dot{f}_{c s i}$ & $\dot{f}_{c s i} \times l / L$ \\
\hline 1 & 1 & 0.6 & 0.3 & 0.031 & 0.281 & 0.1 & 0.0281 & 0.00018497 & 0.00658 & 0.0905 & 98.71 & 0.2597 & 7.75769 & 3.103 \\
\hline 2 & 2 & 0.2 & 0.7 & 0.072 & 0.2 & 0.1 & 0.02 & $6.6667 \mathrm{E}-05$ & 0.00333 & 0.05 & 98.71 & 0.5167 & 8.24952 & 1.1 \\
\hline 3 & 3 & 0.1 & 0.85 & 0.088 & 0.338 & 0.1 & 0.0338 & 0.00032159 & 0.00952 & 0.119 & 98.71 & 0.585 & 7.04862 & 0.47 \\
\hline 4 & 4 & 0.2 & 1 & 0.103 & 0.2 & 0.1 & 0.02 & $6.6667 \mathrm{E}-05$ & 0.00333 & 0.05 & 98.71 & 0.6408 & 8.15642 & 1.087 \\
\hline 5 & 5 & 0.1 & 1.15 & 0.119 & 0.369 & 0.1 & 0.0369 & 0.00041858 & 0.01134 & 0.1345 & 98.71 & 0.6849 & 6.72019 & 0.448 \\
\hline 6 & 6 & 0.2 & 1.3 & 0.134 & 0.2 & 0.1 & 0.02 & $6.6667 \mathrm{E}-05$ & 0.00333 & 0.05 & 98.71 & 0.7131 & 8.10221 & 1.080 \\
\hline 7 & 7 & 0.05 & 1.425 & 0.147 & 0.397 & 0.1 & 0.0397 & 0.00052306 & 0.01316 & 0.1487 & 98.71 & 0.7134 & 6.45419 & 0.215 \\
\hline \multirow[t]{2}{*}{8} & 8 & 0.05 & 1.475 & - & 0.4 & 0.1 & 0.04 & 0.00053333 & 0.01333 & 0.15 & 98.71 & 0.7309 & 6.42646 & 0.214 \\
\hline & $\sum l i$ & 1.5 & & & & & & & & & & & $\dot{\hat{c} c S}$ & 7.718 \\
\hline
\end{tabular}
losses are: $\triangle P F T=\Delta f P C R+\Delta f S H+\Delta f P R=124.622 \mathrm{MPa}$

$$
f_{p e}=f_{p s}-\triangle P F T=872.438 \mathrm{MPa}
$$

The same calculations are repeated for all beams. Table V. shows the prestress losses by the proposed method and stresses in prestressed openings. For simplification reasons, the equivalent trapezoidal shape has the same area as the original opening and uniform posts are considered. The same simplification is used for Group D, where equivalent rectangulars are positioned.

TABLE III. CALCULATION STEPS OF CREEP LOSS FOR BEAM PGT6 (ALL DIMENSIONS ARE IN m)

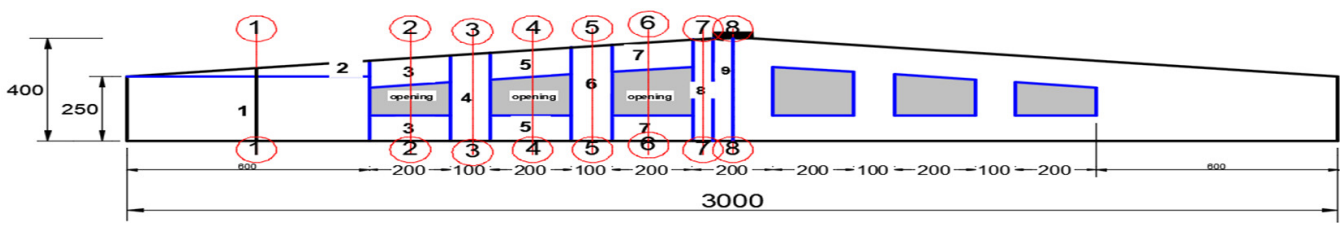

(a)

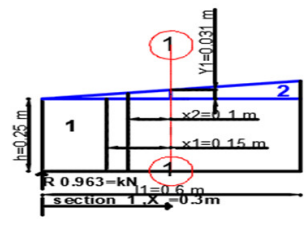

(b)

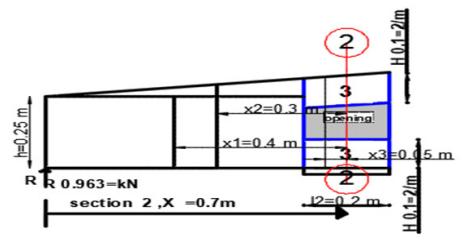

(c)

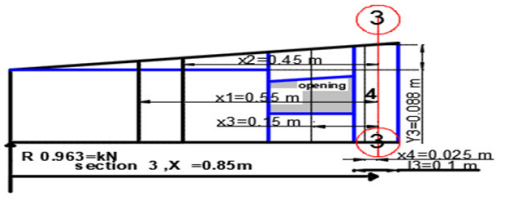

(d)

Fig. 4. Dividing the beam to a set of segments. (a) Details and number of segments, (b) section 1-1, (c) section 2-2, (d) section 3-3 
TABLE IV. CALCULATION STEPS OF SHRINKAGE LOSS FOR BEAM PGT6 (ALL DIMENSIONS ARE IN m)

\begin{tabular}{|c|c|c|c|c|c|c|c|c|c|c|c|}
\hline Part No. & $\boldsymbol{l}$ & $\boldsymbol{X}_{\boldsymbol{i}}$ & $\boldsymbol{Y}_{\boldsymbol{i}}$ & $\boldsymbol{H}_{\boldsymbol{i}}$ & $\boldsymbol{V}_{\boldsymbol{i}}$ & $\boldsymbol{S}_{\boldsymbol{i}}$ & $\boldsymbol{K S H}$ & $\boldsymbol{E}_{\boldsymbol{p s}}$ & $\boldsymbol{R} \boldsymbol{H}$ & $\Delta f \boldsymbol{S H}_{\boldsymbol{i}}$ & $\Delta f \boldsymbol{S H}_{\boldsymbol{i}} \times \boldsymbol{L}_{\boldsymbol{i}} / \boldsymbol{L}_{\text {total }}$ \\
\hline 1 & 600 & 300 & 31.034 & 281.03 & 28103 & 762.069 & 0.77 & 197500 & 70 & 34.0994 & 13.639 \\
\hline 2 & 200 & 700 & - & 200 & 20000 & 800 & 0.77 & 197500 & 70 & 35.1658 & 4.688 \\
\hline 3 & 100 & 850 & 87.931 & 337.93 & 33793 & 875.862 & 0.77 & 197500 & 70 & 33.9463 & 2.263 \\
\hline 4 & 200 & 1000 & - & 200 & 20000 & 800 & 0.77 & 197500 & 70 & 35.1658 & 4.688 \\
\hline 5 & 100 & 1150 & 118.97 & 368.97 & 36897 & 937.931 & 0.77 & 197500 & 70 & 33.8785 & 2.2585 \\
\hline 6 & 200 & 1300 & - & 200 & 20000 & 800 & 0.77 & 197500 & 70 & 35.1658 & 4.688 \\
\hline 7 & 50 & 1425 & 147.41 & 397.41 & 39741 & 994.828 & 0.77 & 197500 & 70 & 33.8237 & 1.127 \\
\hline 8 & 50 & 1475 & & 400 & 40000 & 1000 & 0.77 & 197500 & 70 & 33.819 & 1.127 \\
\hline$\sum L$ & 1500 & & & & & & & & & $4 f S H$ & 34.482 \\
\hline
\end{tabular}

TABLE V. PRESTRESS LOSSES BASED ON THE PROPOSED METHOD AND STRESSES IN PRESTRESSED CONCRETE BEAMS UP TO THE MOMENT OF TESTING

\begin{tabular}{|c|c|c|c|c|c|c|c|c|c|c|c|c|c|c|c|c|}
\hline \multirow{3}{*}{ Group } & \multirow{3}{*}{ Beam } & \multirow{2}{*}{\multicolumn{3}{|c|}{\begin{tabular}{|c|} 
Instantaneous losses \\
(1)
\end{tabular}}} & \multicolumn{6}{|c|}{ Time dependent losses (2) } & \multirow{3}{*}{$\triangle P F T$ (II) } & \multirow{3}{*}{$f p s$} & \multirow{3}{*}{ fpe } & \multirow{3}{*}{$\begin{array}{c}\triangle P F T \\
(1)+(2)\end{array}$} & \multirow{3}{*}{\begin{tabular}{|c|} 
Prestress \\
loss/initial \\
prestress (\%)
\end{tabular}} & \multirow{3}{*}{$\begin{array}{l}\text { Increasing } \\
\text { ratio of } \\
\text { losses } \%(1)\end{array}$} \\
\hline & & & & & \multicolumn{3}{|c|}{ At transfer (I) } & \multicolumn{3}{|c|}{ At the age of test (II) } & & & & & & \\
\hline & & $\Delta f P A$ & $\triangle f E S$ & $\Delta f P F$ & $\Delta f P R$ & $\triangle f C R$ & $\Delta f S H$ & $\triangle f P R$ & $\triangle f C R$ & $\Delta f S H$ & & & & & & \\
\hline \multirow{4}{*}{ A } & PGB(ref) & 98.75 & 0 & 6.25 & 6.89 & 0 & 0 & 7.65 & 76.47 & 33.975 & 118.095 & 997.06 & 878.965 & 229.985 & 20.608 & 0 \\
\hline & PGT6 & 98.75 & 0 & 6.25 & 6.89 & 0 & 0 & 8.02 & 82.12 & 34.482 & 124.622 & 997.06 & 872.438 & 236.512 & 21.193 & 2.838 \\
\hline & PGT8 & 98.75 & 0 & 6.25 & 6.89 & 0 & 0 & 8.18 & 81.54 & 34.48 & 124.2 & 997.06 & 872.86 & \begin{tabular}{|l|}
236.09 \\
\end{tabular} & 21.155 & 2.654 \\
\hline & PGT10 & 98.75 & 0 & 6.25 & 6.89 & 0 & 0 & 8.25 & 80.9 & 34.4 & 123.55 & 997.06 & 873.51 & 235.44 & 21.097 & 2.371 \\
\hline \multirow{3}{*}{ B } & PGB(ref) & 98.75 & 0 & 6.25 & 6.89 & 0 & 0 & 7.65 & 76.47 & 33.975 & 118.095 & 997.06 & 878.965 & 229.985 & 20.608 & 0 \\
\hline & PGTH6 & 98.75 & 0 & 6.25 & 6.89 & 0 & 0 & 8.28 & 82.284 & 34.61 & 125.174 & 997.06 & 871.886 & 237.064 & 21.243 & 3.078 \\
\hline & PGTH10 & 98.75 & 0 & 6.25 & 6.89 & 0 & 0 & 8.39 & 81.028 & 34.505 & 123.923 & 997.06 & 873.136 & 235.813 & 21.130 & 2.534 \\
\hline \multirow{4}{*}{$\mathrm{C}$} & PGB(ref) & 98.75 & 0 & 6.25 & 6.89 & 0 & 0 & 7.65 & 76.47 & 33.975 & 118.09 & 997.06 & 878.965 & 229.985 & 20.608 & 0 \\
\hline & PGP6 & 98.75 & 0 & 6.25 & 6.89 & 0 & 0 & 8.42 & 81.204 & 34.43 & 124.05 & 997.06 & 873.006 & 235.944 & 21.142 & 2.591 \\
\hline & PGP8 & 98.75 & 0 & 6.25 & 6.89 & 0 & 0 & 8.45 & 80.84 & 34.43 & 123.72 & 997.06 & \begin{tabular}{|l|}
873.34 \\
\end{tabular} & 235.61 & 21.112 & 2.445 \\
\hline & PGP10 & 98.75 & 0 & 6.25 & 6.89 & 0 & 0 & 8.47 & 80.429 & 34.169 & 123.06 & 997.06 & 873.992 & 234.958 & 21.054 & 2.162 \\
\hline \multirow{3}{*}{ D } & PGB(ref) & 98.75 & 0 & 6.25 & 6.89 & 0 & 0 & 7.65 & 76.47 & 33.975 & 118.095 & 997.06 & 878.965 & 229.985 & 20.608 & 0 \\
\hline & PGC1 & 98.75 & 0 & 6.25 & 6.89 & 0 & 0 & 8.5 & 84.953 & 34.365 & 127.818 & 997.06 & 869.242 & 239.708 & 21.479 & 4.227 \\
\hline & PGC2 & 98.75 & 0 & 6.25 & 6.89 & 0 & 0 & 8.53 & 80.915 & 34.23 & 123.675 & 997.06 & 873.385 & 235.565 & 21.108 & 2.426 \\
\hline
\end{tabular}

\section{COMPARISON BETWEEN THE EXPERIMENTAL AND THE PROPOSED METHOD'S RESULTS}

As demonstrated in Table VI, the experimental results converge to the ones of the proposed method. The ratio of experimental to the proposed method's results ranged from $84.749 \%$ to $95.607 \%$ denoting the validity of the proposed estimation.

TABLE VI. RESULT COMPARISON

\begin{tabular}{|c|c|c|c|c|}
\hline \multirow{3}{*}{ Group } & Beam & $\begin{array}{c}\text { Experimental } \\
\text { loss }\end{array}$ & $\begin{array}{c}\text { Proposed } \\
\text { loss }\end{array}$ & $\begin{array}{c}\text { Experimental loss / } \\
\text { Proposed loss \% }\end{array}$ \\
\hline \multirow{4}{*}{ A } & PGB & 194.909 & 229.985 & 84.749 \\
\cline { 2 - 5 } & PGT6 & 217.982 & 236.512 & 92.165 \\
\cline { 2 - 5 } & PGT8 & 212.406 & 236.09 & 89.968 \\
\cline { 2 - 5 } & PGT10 & 208.538 & 235.44 & 88.574 \\
\hline \multirow{4}{*}{ B } & PGB & 194.909 & 229.985 & 84.749 \\
\cline { 2 - 5 } & PGTH6 & 226.650 & 237.064 & 95.607 \\
\cline { 2 - 5 } & PGTH8 & 221.720 & 236.532 & 93.738 \\
\cline { 2 - 5 } & PGTH10 & 218.937 & 235.81377 & 92.843 \\
\hline \multirow{4}{*}{ C } & PGB & 194.909 & 229.985 & 84.749 \\
\cline { 2 - 5 } & PGP6 & 217.028 & 235.944 & 91.983 \\
\cline { 2 - 5 } & PGP8 & 210.760 & 235.61 & 89.453 \\
\cline { 2 - 5 } & PGP10 & 206.688 & 234.958 & 87.968 \\
\hline \multirow{4}{*}{ D } & PGB & 194.909 & 229.985 & 84.749 \\
\cline { 2 - 5 } & PGC1 & 216.316 & 239.708 & 90.241 \\
\cline { 2 - 5 } & PGC2 & 207.123 & 235.565 & 87.926 \\
\cline { 2 - 5 } & PGTC3 & 202.382 & 233.548 & 86.656 \\
\hline
\end{tabular}

\section{CONCLUSION}

- Increasing the number of quadratic openings along the beam length from 6 to 8 and then to 10 decreased the prestress losses by an average of $2.54 \%$ and $4.166 \%$, respectively.

- The prestress losses decrease with reducing size of the circular openings by $17 \%$ and $33 \%$ from $4.25 \%$ to $6.441 \%$.

- Decreasing the depth of both upper and lower chords for perforated beams by $25 \%$, i.e. by increasing openings' height, led to increase prestress losses by an average of $4.258 \%$.

- The average decrease in the prestress losses in beams having inclined posts in comparison with those having vertical ones was $2.593 \%$.

- The average losses decrease in prestressing force for beams with circular openings in comparison with that of quadratic ones was $2.217 \%$.

- The result of the proposed estimated method converges with the experimental results. This accordance ranged from $84.749 \%$ to $95.607 \%$. 


\section{APPENDIX}

$A_{C} \quad$ Area of net concrete section

$A_{p s} \quad$ Area of prestressed steel in tension zone

Ec Modulus of elasticity of concrete

Eps Modulus of elasticity of prestressed steel

$f_{p i} \quad$ Initial prestress stress in prestressed steel

$f_{p j} \quad$ Stress in prestressed steel at jacking stage

$f^{\prime} c \quad$ Cylinder concrete compressive strength at 28 days

$f_{p s} \quad$ Stress in prestressed steel at nominal flexural strength

RH Relative humidity

Second moment of area of net concrete section about an axis through its centroid

$k \quad$ Wobble coefficient

$M D \quad$ Dead load moment

$P_{i} \quad$ Initial prestress force

$\mu \quad$ Curvature friction coefficient

Total angular change of prestressing tendon profile in radians from tendon jacking end to any point $\mathrm{x}$

$\triangle A \quad$ Slip in tendon from anchorage

$\triangle f_{P A} \quad$ Prestress losses due to anchorage seating

$\triangle f_{E S} \quad$ Prestress losses due to elastic shortening

$\triangle f_{P F} \quad$ Prestress losses due to friction

$\Delta \mathrm{f}_{\mathrm{PR}} \quad$ Prestress losses due to relaxation

\section{REFERENCES}

[1] A. E. Naaman, "Computation of prestress losses", in: Prestressed Concrete Analysis and Design, Techno Press 3000, pp. 445-514, 2004

[2] S. A. Youakim, A. Ghali, S. E. Hida, V. M. Karbhari, "Prediction of long-term prestress losses”, PCI Journal, Vol. 52, No. 2, pp. 116-130, 2007

[3] A. Shokoohfar, A. Rahai, "Prediction model of long-term prestress loss interaction for prestressed concrete containment vessels", Archives of Civil and Mechanical Engineering, Vol. 17, No. 1, pp. 132-144, 2017

[4] E. G. Nawy, "Partial loss of prestress", in: Prestressed Concrete: A Fundamental Approach, Prentice Hall, 5th Edition, pp. 73-105, 2009

[5] D. M. H. Al-Fendawy, Strengthening of reinforced concrete t-beams using external post-tensioning, MSc Thesis, University of Baghdad, 2014

[6] M. A. Mansur, K. H. Tan, Concrete beams with openings: analysis and design, CRC Press, 1999

[7] N. K. Oukaili, A. Shammari, "Response of reinforced concrete beams with multiple web openings to static load", Fourth Asia-Pacific Conference on FRP in Structures, Melbourne, Australia, December 1113, 2013

[8] V. N. Baykov, E. E Seagal, Reinforced concrete structures, Stroyizdat, 1991

[9] M. A. J. Hassan, A. F. Izzet, "Serviceability of reinforced concrete gable roof beams with openings under static loads", Engineering, Technology \& Applied Science Research, Vol. 9, No. 5, pp. 4813-4817, 2019

[10] M. A. J. Hassan, A. F. Izzet, "Experimental and numerical comparison of reinforced concrete gable roof beams with openings of different configurations", Engineering, Technology \& Applied Science Research, Vol. 9, No. 5, pp. 5066-5073, 2019

[11] B. Aykac, S. Aykac, I. Kalkan, B. Dundar, H. Can, "Flexural behavior and strength of reinforced concrete beams with multiple transverse openings", ACI Structural Journal, Vol. 111, No. 2, pp. 267-278, 2014

[12] P. S. Samir, Precast/prestressed concrete Truss-Girder for roof applications, MSc Thesis, University of Nebraska-Lincoln, 2013

[13] B. M. Dawood, H. A. Al-Katib, "Flexural strength of prestressed concrete beams with openings and strengthened with CFRP sheets", International Journal of Scientific \& Technology Research, Vol. 4, No. 6, pp. 161-172, 2015.

[14] M. M. Mohammed, Strength, cracking and deformability of partially prestressed concrete beams under repeated loading, $\mathrm{PhD}$ Thesis, University of Baghdad, 2018
[15] ACI-318, Building code requirements for structural concrete (ACI $318 \mathrm{M}-2014)$ and commentary, American Concrete Institute, Farmington Hills

[16] P. Zia, H. Kent Preston, N. L. Scott, E. B. Workman, "Estimating prestress losses", Concrete International, Vol. 1, No. 6, pp. 32-38, 1975 